\title{
Energetic and exergetic analysis of a new compact trigeneration system run with liquefied petroleum gas
}

\author{
Nestor Proenza Pérez*, Marlene Titosse Sadamitsu, Jose Luz Silveira, \\ Julio Santana Antunes, Celso Eduardo Tuna, Atilio Erazo Valle, Natalia Faria Silva \\ São Paulo State University, Faculty of Engineering at Guaratinguetá, Department of Energy, (LOSE) Laboratory of Optimization of Energy Systems, Brazil
}

\section{A R T I C L E I N F O}

\section{Article history:}

Received 10 February 2015

Received in revised form

22 June 2015

Accepted 23 June 2015

Available online 15 July 2015

\section{Keywords:}

Cogeneration

Energetic

Exergetic

Internal combustion engine

Efficiencies

\begin{abstract}
A B S T R A C T
In this study, the first and second laws of thermodynamics are used to analyze the quantity and quality of energy in a small compact trigeneration system. This combined cycle is composed of a little reciprocating ICE model GM, 1.0 CORSA (internal combustion engine), using LPG (liquefied petroleum gas) as fuel, HE1 and HE2 (two heat exchangers) and an AM (absorption machine) using ammonia-water as working fluid mixture. The mass and energy balance equations of the engine and subsystems are reviewed in detail. Exergy of each involved stream is calculated and the exergetic balance of each subsystem is presented, as well as the global system, identifying where and why losses and irreversibilities occurs. Efficiencies based on the second law of thermodynamics are calculated for each subsystem and compared. Special attention is given to identification and quantification of second law efficiencies and the irreversibilities of various processes and subsystems. The determination of the irreversibilities in each subsystem is particularly important since they are not identified in traditional first law analysis. Furthermore, this study revealed that the combustion was the most important contributor to the system inefficiency representing $36.0 \%$ of the total exergy input and $73 \%$ of the total exergy destruction. The exergetic efficiency of the trigeneration system is determined to be $51.19 \%$.
\end{abstract}

(c) 2015 Elsevier Ltd. All rights reserved.

\section{Introduction}

The Cogeneration Systems or CHP (Combined Heating and Power) and trigeneration or CCHP (Combined Cooling Heating and Power) as well known, are technologies with a rapid growth due to the ability to solve power supply problems more efficiently, economical and less polluting to the environment than those traditionally known and used for power supply and energy separately [1]. Cogeneration and trigeneration may be defined as the simultaneous production of electrical or mechanical energy and useful thermal or cooling energy from a single energy source, such as oil, coal, natural or liquefied gas, biomass, or solar as per Sonar et al. [1] and Silveira et al.[2]. These two technologies main objective is that most of the energy contained in the fuel is used, instead of only a small part. Thus, a more economical method is obtained compared to the systems where electricity and heat are separately produced. The efficiency of energy production can be

\footnotetext{
* Corresponding author. Tel.: +55 1231232239.

E-mail address: nestorproenza@yahoo.es (N. Proenza Pérez).
}

increased from current levels that vary from $35 \%$ to $55 \%$ in the conventional power plants to over $80 \%$ in the CHP and CCHP systems [3].

In Brazil there is a large potential for the use of CHP and CCHP systems especially in the industrial sector according to Soares et al. [4]. In recent years the Brazilian government has encouraged the use of such technologies based on international experiences of countries like France, the UK, Denmark, Finland, the Netherlands and the US where incentive policies were created for fossil fuels and renewable sources use. In Brazil was created in the year 2000 the Cogeneration Incentive Program through Edict 212/2000, with a short term objective to provide private investment incentives in CHP systems providing enhanced thermoelectric generation capacity installed in the country [5]. Later in the year 2002 was created the Incentive Program for Alternative Sources of Electric Energy (PROINFA) by Law 10,438 to stimulate the electricity generation from renewable energy sources such as wind, biomass, and hydric, where the use of cogeneration systems associated with these systems is promoted through public financing incentives available in the Brazilian Development Bank (BNDES), direct subsidies, including taxes and import fees reduction cogeneration 


\begin{tabular}{|c|c|c|c|}
\hline \multicolumn{2}{|c|}{ Nomenclature } & \multirow{2}{*}{\multicolumn{2}{|c|}{$\begin{array}{ll}0 & \text { reference condition } \\
\text { am } & \text { arithmetic mean } \\
\text { eff } & \text { effective }\end{array}$}} \\
\hline$\dot{m}$ & mass flow rate $[\mathrm{kg} / \mathrm{s}]$ & & \\
\hline $\mathrm{T}$ & temperature $[\mathrm{K}]$ & th & thermal \\
\hline $\mathrm{H}$ & specific enthalpy $[\mathrm{kJ} / \mathrm{kg}]$ & $\mathrm{T}$ & total \\
\hline$S$ & specific entropy [kJ/kg] & ch & chemical \\
\hline Q & heat $[\mathrm{kW}]$ & $\mathrm{u}$ & net work \\
\hline W & work $[\mathrm{kW}]$ & $\mathrm{cW}$ & cool water \\
\hline A,B,C,D & heat capacities constant & $\mathrm{HE}$ & heat exchanger \\
\hline $\mathrm{R}$ & universal gas constant $[\mathrm{J} / \mathrm{mol} \mathrm{K}]$ & $\mathrm{AM}$ & absorption machine \\
\hline E & specific exergy $[\mathrm{kJ} / \mathrm{kg}]$ & dest & destroyed \\
\hline $\mathrm{X}$ & molecular fraction & gen & generation \\
\hline $\mathrm{Cp}$ & average specific heat [kJ/kg K] & & \\
\hline $\mathrm{E}$ & total exergy $[\mathrm{kW}]$ & \multicolumn{2}{|c|}{ Superscript } \\
\hline LHV & low heating value $[\mathrm{kJ} / \mathrm{kg}]$ & $\mathrm{n}$ & Enesimo \\
\hline \multicolumn{2}{|c|}{ Subscript } & \multicolumn{2}{|c|}{ Greek symbols } \\
\hline in & input & $\Psi$ & degree of thermodynamic perfection \\
\hline out & output & $\xi$ & rational efficiency \\
\hline $\mathrm{i}$ & any component & $\eta$ & energy efficiency \\
\hline $\mathrm{vc}$ & control volume & $\emptyset$ & Coefficient \\
\hline ex & exhaust gas & & \\
\hline
\end{tabular}

equipment as well as the guarantee of long-term contracts and attractive selling prices for cogeneration companies [6].

Several works have presented compact cogeneration and trigeneration systems based on internal combustion engine for production of heat and power. Giani Bidini et al. [7] report exergetic analysis in the new type cogeneration plants. This new plant is a combination of two interconnected combined heat and power systems: a reciprocating internal combustion engine cogenerator as the topping cycle and a Rankine cycle cogenerator which operates as the bottoming cycle on the exhaust gases from the ICE. The electrical and energetic efficiencies were $35.1 \%$ and $44.9 \%$ respectively, while the exergetic efficiencies it was $39.9 \%$. The study of the small compact cogeneration system with an absorption refrigeration system working with different fuels as hydrated ethanol, diesel oil and natural gas is reported by Ref. [8], the comparative technical-economical analysis is made. Another work report for Rosen et al. [9] using a cogeneration system in the district energy systems in the city of Edmonton, Canada, realized the energetic and exergetic analysis considered three possibilities for the provision of central chilling services: electric chillers, single-effect absorption chillers and double-effect absorption chillers. The energetic analysis results reporting efficiencies vary significantly from 83 to $94 \%$, however exergetic efficiency values were almost equal varying between 28 and $29 \%$. R. E. Klaassen and M. K. Patel [10], performs a technical economic assessment of CHP systems working with natural gas related to district heat, estimating the primary energy savings through different methods compared to traditional systems, similar work is reported by Chunhui Liao et al. [11] but using coal as fuel. The combination of fuels such as $\mathrm{H}_{2}$ and natural gas in residential CHP systems is reported by Gianluigi Lo Basso et al. [12], showing that the overall electrical efficiency increases with the mixture but the total thermal power decreases. Optimization studies in the field of trigeneration systems are reported by P. Arcuri et al. [13] and A. Piacentino et al. [14] where using different mathematical models, simulate the best plant design in technology terms, size, and operation time defining the best operating strategy to be employed.
Based on our search in the open literature the CHP and CCHP technologies are widely known and studied especially when they use natural gas as the primary fuel however there are not many papers with this reported system using LPG (Liquefied Petroleum Gas). The main objetive of this study is precisely the first and second Law of thermodynamics use to analyze the energy quantity and quality of a small trigeneration system consisting of a four-cylinder, with MPFI - Delphi system injection spark engine using LPG as fuel.

An estimation done by the PDE (Ten year Expansion Plan) [15] expects that over the next 10 years Brazil will experience an extraordinary oil production expansion due to the large investment in this sector (offshore production) about to triple its production from 2.1 million barrels per day in 2010 to 6.1 million barrels per day in 2020, the creation of new refineries will help increase the LPG production, covering domestic demand fully, even to export this derivative [16]. As the studies that aim to use this energy vector are of vital importance today.

\section{Liquefied petroleum gas as fuel}

LPG (Liquefied petroleum gas) was first put into use as an internal combustion engine fuel in the 1930s when a vehicle was first run on LPG in the eastern coast of the USA. Due to its good performance, interest was created among researchers to introduce it in a larger scale as an alternative/supplement to gasoline.

The use of LPG as alternative fuel to gasoline is common practice in spark ignition engines. While the main driving force for LGP use remains low cost, is usually less expensive than gasoline, to the end user, and its favorable pollutant emissions (they are less using LPG instead of gasoline), can produce quantities significantly less than some harmful emissions, in particular greenhouse gas carbon dioxide, probably it will be in the medium term, increase interest in LPG as fuel of the IC engine.

Although LPG fuel is used with new generation conversion systems in spark ignition engines, a little reduction in power output of engine occurs. The reason for this reduction is the decrease in the volumetric efficiency of the engine as the result of using LPG which expands 230-267 times while passing to the gas phase from liquid 
phase. When using LPG in gas state in spark ignition engines, the volumetric efficiency is more explicitly less than those when using gasoline and the volumetric efficiency of LPG in gas phase is $4-7 \%$ lower than usage of gasoline [17].

The LPG is a mixture of hydrocarbons, mostly propane $\left(\mathrm{C}_{3} \mathrm{H}_{8}\right)$ and butane $\left(\mathrm{C}_{4} \mathrm{H}_{10}\right)$ isomers. The composition of LPG depends on its end use and varies greatly according to season, country, properties of the crude oil/gas supply used and refining process. The LPG commercially available for the automotive market has to comply with a standard that does not define compositions, but limits fuel properties only. Usually, countries having relatively cold climates tend to use a higher propane percentage, while warmer countries mostly use butane. The composition used in Brazil is 50\% propane and $50 \%$ of n-butane [18].

Caliskan et al. [19] presents an excellent review on energy and exergy analysis of Otto and diesel engines from 1963 to 2008. The test engines had different cylinders numbers, speeds and rated powers. According to the authors, the best exergetic efficiency for a turbo charged diesel engine was about $30 \%$. In a study by Celik and Balki [20], compression ratio were increased from 5:1 to 9:1 in a single cylinder engine and possibilities of performance improvement for using of LPG were investigated experimentally. Tira H.S. et al. [21] report an experimental study used a liquefied petroleum gas in diesel dual fuel internal combustion engine for understand the impact of the properties of the direct injection diesel fuels as well as the combustion characteristics, engine performance and emissions. In this sense, Lata and Misra [22], Lata et al. [23], Lata and Misra [24] and Lata et al. [25] and Chintala and Subramanian [26] present theoretical and experimental studies related to the use of hydrogen and liquefied petroleum gas as secondary fuels in dual fuel diesel engines. These papers contain reported information about the ignition delay, combustion, efficiency and emissions pollutant.

\section{Operation of the gas engine powered cogeneration plant}

The compact cogeneration system, see Fig. 1, used in this work is a "stand alone" system, not connected to the grid. This is especially useful in countries like Brazil, where there is not the possibility to connect the whole territory to the national grid, due

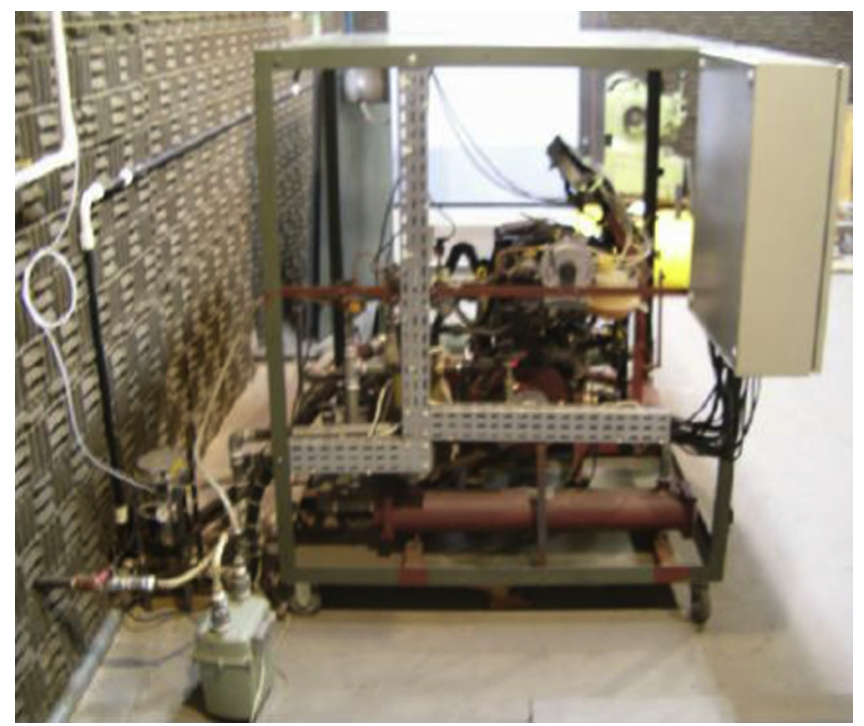

Fig. 1. Compact small trigeneration system. to its vastness. This system is situated in the Energetic Optimization Systems Laboratory (LOSE) in State University of Sao Paulo and it is constituted by a little internal combustion engine model GM, 1.0 CORSA, see Table 1, manufacture date "1998", four strokes, with MPFI-Delphi injection system, associated with an electrical generator and two heat exchangers, one heat exchanger makes the function of radiator, is coupled at the engine system cooling, from which the water thermal energy is used for hot water production. The exhaust gases are directed into a second heat exchanger in which their temperature is reduced to a suitable level to run the absorption chiller with a capacity of 5 TR, mark ROBUR, the characteristic of this heat exchanges can be seen in Table 2. The engine study has a "Rodogás" fuel feeding system (pressure reducer) which allows the operation both on LPG or VNG and even on gasoline. Rodogás is an instrument, model TE-01, with capacity for up to $43 \mathrm{~m}^{3} / \mathrm{h}$ of fuel, this system serves for engines up to 120 HP. A generator is coupled to the engine through a pulley and belt which receives the mechanical energy produced by the combustion engine. The electric generator (alternator three phase), works at a frequency of $60 \mathrm{kHz}$, has 4 poles, power of $10 \mathrm{~kW}-12.5 \mathrm{~kW}$ with a current at $32.8 \mathrm{~A}$ and $220 \mathrm{~V}$, rated values. Before going to the second heat exchanger the gases pass through a catalyst in order to reduce pollution emission. The heat expelled in the reducing temperature process is used for hot water production, in addition to the produced in the engine cooling system (jacket water system). The absorption system works with an ammonia-water mixture and it produces cold water, which can be used in human consumption water machines or fan coils. The electrical power from the generator is dissipated in the resistive load banks. Pressure, temperature and flow gauges are installed in different points of the system, to enable the necessary calculations. The data captured by acquisition system, see Table 3, are sent to a computer through an AQDADOS system, where electrical signals are converted into temperature, pressure and flow measurements, calculations of entropy and enthalpy of each point were performed with the EES (Engineering Equation Solver) software. The experimental data were collected using steady-state tests which enable accurate measurements of air, fuel, and cooling and hot water flow rates, engine load, and all the relevant temperatures.

Table 1

The GM, 1.0 CORSA engine technical specifications.

\begin{tabular}{ll}
\hline Engine manufacturer & Opel \\
\hline Coolant type & Water \\
Valves per cylinder & 4 \\
Engine displacement & $998 \mathrm{cc}$ \\
Bore & $73.4 \mathrm{~mm}$ \\
Stroke & $78.6 \mathrm{~mm}$ \\
Compression ratio & $10.5: 1$ \\
Fuel system type & Motronic MPFi \\
Aspiration type & Normal \\
Maximum engine power & $59 \mathrm{HP}(44 \mathrm{~kW})$ \\
Engine torque at max. engine power rpm & $75 \mathrm{~N} \cdot \mathrm{m}(5600 \mathrm{~d} / \mathrm{d})$ \\
stoichiometric air-fuel ratio & $15: 1$ \\
\hline
\end{tabular}

Table 2

Principal characteristics

\begin{tabular}{ll}
\hline Heat exchangers & \\
\hline Model & Shell and tube water/water and gas/water \\
Number of tubes & 40 (water/water) and 76 (gas/water) \\
Diameter of tubes & $9.525 \mathrm{~mm}$ (both) \\
Material of tubes & Carbon steel (water/water) and copper (gas/water) \\
Thickness of tubes & $0.79 \mathrm{~mm}$ (both) \\
Number of deflectors & 7 (water/water) and 3 (gas/water) \\
\hline
\end{tabular}


Table 3

Experimental data.

\begin{tabular}{llrcll}
\hline Point & Flow & $\dot{m}(\mathrm{Kg} / \mathrm{h})$ & $\mathrm{T}\left({ }^{\circ} \mathrm{C}\right)$ & $\mathrm{h}(\mathrm{kJ} / \mathrm{kg})$ & $\mathrm{s}(\mathrm{kJ} / \mathrm{kg} \mathrm{K})$ \\
\hline 1 & LPG & 3.798 & 25 & - & - \\
2 & Air & 45.955 & 25 & - & - \\
3 & Exhaust gas & 49.554 & 541.1 & 883.09 & 7.954 \\
4 & Exhaust gas & 49.554 & 307 & 647.17 & 7.572 \\
5 & Exhaust gas & 49.554 & 149 & 423.19 & 7.232 \\
6 & Water & 1980 & 90.3 & 378.2 & 1.196 \\
7 & Water & 1980 & 84 & 351.8 & 1.123 \\
9 & Water & 265 & 25 & 104.8 & 0.3669 \\
10 & Water & 265 & 65 & 272.1 & 0.8935 \\
11 & Water & 66.4 & 25 & 104.8 & 0.3669 \\
12 & Water & 66.4 & 65 & 272.1 & 0.8935 \\
13 & Water & 87.19 & 25 & 104.8 & 0.3669 \\
14 & Water & 87.19 & 7 & 29.51 & 0.1063 \\
\hline
\end{tabular}

\section{Experimental}

Fig. 2 shows the small cogenerator system basic layout. This figure indicates the flows required for the system operation, and the CHP applications considered for this case. The engine run with LPG as fuel with a consumption of $3.798 \mathrm{~kg} / \mathrm{h}$, generating an output shaft of $12.8 \mathrm{~kW}$ at $1800 \mathrm{rpm}$ and drives an electric generator with nominal performance of 95\%. The LHV (lower heating value) of the fuel is $46,473 \mathrm{~kJ} / \mathrm{kg}$ [27]. The engine works with a real air-fuel ratio 12.1:1. The cylinder cooling system is pressurized at $140 \mathrm{kPa}$ and moves a water flow of $1980 \mathrm{~kg} / \mathrm{h}$. The outgoing temperature is $90^{\circ} \mathrm{C}$ and the return temperature is $84^{\circ} \mathrm{C}$. In Table 3 are reported the experimental data for each subsystems. This hot water passes through the HE1, type water/water (heat exchanger one), with an effectiveness of $85 \%$. The carcass is made up of DIN 2440 steel, the tubes, chicanes and mirrors are made up of carbon steel. The mass flow rate of the exhaust gas is $49,55 \mathrm{~kg} / \mathrm{h}$ and the emerges from the engine at a temperature of $541{ }^{\circ} \mathrm{C}$, entering in the HE2, type gas/water (second heat exchanger), with effectiveness of $80 \%$, circulating on the side of the tubes and cooled to $307^{\circ} \mathrm{C}$. Then, with the gases temperature levels required are brought to the generator of the absorption machine initiating the process of refrigeration and producing a cool water at $7^{\circ} \mathrm{C}$. The absorption machine functions on ammonia/water, has a refrigeration capacity of $17.4 \mathrm{~kW}$ ( $5 \mathrm{TR}$ ), consumes the equivalent of $2.55 \mathrm{~kg} / \mathrm{h}$ of LPG, if it is used with direct burning, and has an electrical consumption of $1275 \mathrm{~W}$, manufactured in Italy and marketed by the ROBUR brand, it was adapted to be driven by hot gases, in contrast to conventional systems, where the hot gas is used to generate steam and the steam drives the cooling device. The COP of the system is 0.7. Hydraulic pumps drive the water heated in the heat exchangers while the water used in the absorption machine is fed by gravity. Electrical energy produced in

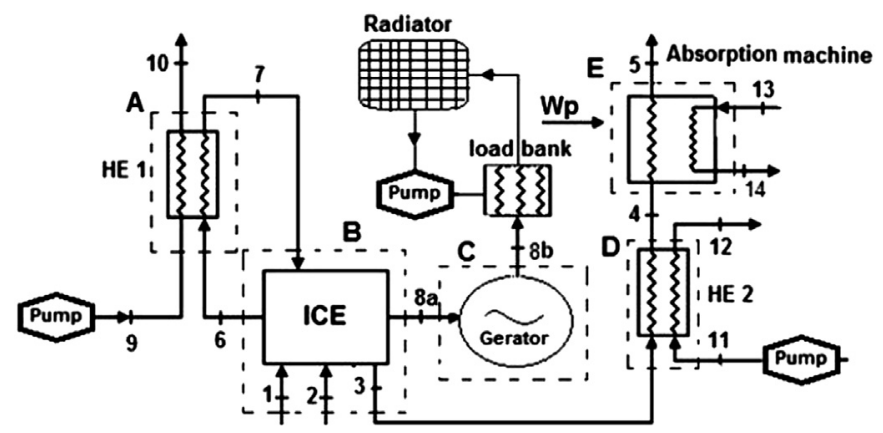

Fig. 2. Experimental installation schematic layout. the generator is dissipated in a resistive load bank submerged in a tank with $500 \mathrm{~L}$ of water and can also operate lamps of $100 \mathrm{~W}$. The Bank consists of 27 resistance of $1 \mathrm{~kW}$ each and to avoid the super heating in the resistance, water passes through a cooling cycle through an air radiator, a pump is responsible to drive back the water to the tank.

\section{Mathematical modeling}

To define the mass flow rate and energy transfer rate at the control surface, mass and energy balances on the small scale cogeneration system are required before the exergy analysis.

Most transient-flow processes can be modeled as a uniform flow process. With the purpose of simplifying the first law calculations of the test engine, the following assumptions were made:

- The engine powered cogeneration system operates in a steadystate condition.

- The ideal gas principles are applied to air and exhaust gases.

- The combustion reaction in gas engine is complete.

- The kinetic and potential energy changes are negligible.

- The temperature and pressure of dead (environmental) state are taken as the ambient conditions.

- Because the state of water in the exhaust is generally vapor in internal combustion engines, the LHV (lower heating value) of the fuel is used.

\subsection{Mass balance}

In Fig. 2 mass and power flows are identified (numbered streams), as well as sub-systems composing the global system (capital letters). These are: heat exchange one (sub-system A), internal combustion engine (sub-system $B$ ), generator (sub-system $C$ ) heat exchanger two (sub-system D), and absorption machine (subsystem E). In all sub-system are considered that all properties are unchanged in time. The total mass flow rate entering in the control volume was assumed to equal the total mass flow rate leaving the control volume. Then we can write:

$\sum_{\text {in }} \dot{m}_{\text {in }}=\sum_{\text {out }} \dot{m}_{\text {out }}$

where the inlet and outlet mass flow rate are represented as $\dot{m}_{i n}$ and $\dot{m}_{\text {out }}$.

\subsection{Energy analysis}

The overall objective of conservation of energy is an efficient use of energy resources. When the cost and availability of fuel is considered is evident that we care about the energy conservation.

The first law of thermodynamics is the principle of conservation of energy. It indicates that when energy is converted from one form to another, none energy is created or destroyed. First Law can be written in generally form as: [28]

$$
\begin{aligned}
\dot{Q}_{c v}+\sum \dot{m}_{\text {in }}\left(h_{\text {in }}+\frac{V_{\text {in }}^{2}}{2}+g Z_{\text {in }}\right)= & \sum \dot{m}_{\text {out }}\left(h_{\text {out }}+\frac{V_{\text {out }}^{2}}{2}+g Z_{\text {out }}\right) \\
& +\dot{W}_{c v}
\end{aligned}
$$

The Eq. (2) allows an assessment of the heat transfer rate that is lost by the engine to the environment, based on the assumptions listed above, this equation can be written as follows: 
$\dot{Q}+\sum \dot{m}_{\text {in }} h_{\text {in }}=\sum \dot{m}_{\text {out }} h_{\text {out }}+\dot{W}$

Then fuel energy rate to the control volume is given by

$Q_{\text {fuel }}=\dot{m} \cdot L H V_{\text {fuel }}$

The equation of complete combustion depends on the chemical composition of the type of fuel. For the complete combustion with the theoretical amount of air given below:

$$
\mathrm{C}_{x} \mathrm{H}_{y}+\mathrm{a}\left(\mathrm{O}_{2}+3.76 \mathrm{~N}_{2}\right) \rightarrow b \mathrm{CO}_{2}+c \mathrm{H}_{2} \mathrm{O}+d \mathrm{O}_{2}+e \mathrm{~N}_{2}
$$

The values of the unknown coefficients a, b, c, d and e in Equation (5) can be determined by applying the conservation of mass principle to each element with the use of the fuel, chemical formulas. Then in the case of use LPG with 50\% of methane and 50\% of $n$-butane as fuel the equation is:

$$
\begin{aligned}
0.5 \mathrm{C}_{3} \mathrm{H}_{8}+0.5 \mathrm{C}_{4} \mathrm{H}_{10} & +\alpha\left(\mathrm{O}_{2}+3.76 \mathrm{~N}_{2}\right) \rightarrow 3.5 \mathrm{CO}_{2} \\
& +4.5 \mathrm{H}_{2} \mathrm{O}+1.15 \mathrm{O}_{2}+25.94 \mathrm{~N}_{2}
\end{aligned}
$$

The exhaust gas loss was calculated using equation (7)

$Q_{e x}=\sum_{i=1}^{n} n_{i} \bar{C}_{p i}\left(T_{e x}-T_{0}\right)$

The specific heat of the exhaust gas was calculated by an empirical equation [29]

$\bar{C}_{p}=R\left(A+B T_{a m}+\frac{C}{3}\left(4 T_{a m}^{2}-T_{1} T_{2}\right)+\frac{D}{T_{1} T_{2}}\right)$

where $\mathrm{T}_{\mathrm{am}}=\left(\mathrm{T}_{1}+\mathrm{T}_{2}\right) / 2$ is the arithmetic mean temperature, $\mathrm{T} 1 \mathrm{and}$ T2 are the input and output exhaust gas temperature in the subsystems D and E. A, B, C and D are heat capacities constants for the concerned gases [29], $\bar{C}_{p}$ is the average specific heat over temperature change, and $R$ is the universal gases constant $R=8,31 \mathrm{~J} / \mathrm{mol} \mathrm{K}$, in Fig. 3 can be observed the behavior of the specific heat of the exhaust gas.

The energy input accompanying the combustion air can be ignored since the combustion air is very close to the standard reference state (dead state), for engine applications the (environmental) pressure and temperature conditions are usually taken to be $\mathrm{P}_{0}=101.325 \mathrm{kPa}$ and $\mathrm{T}_{0}=298.15 \mathrm{~K}$, and if chemical availability is also taken into account, then the molar composition of the environment is: $20.35 \% \mathrm{O}_{2}, 75.67 \% \mathrm{~N}_{2}, 0.03 \% \mathrm{CO}_{2}, 3.03 \% \mathrm{H}_{2} \mathrm{O}$ and $0.92 \%$ various other substances $[30,31]$.

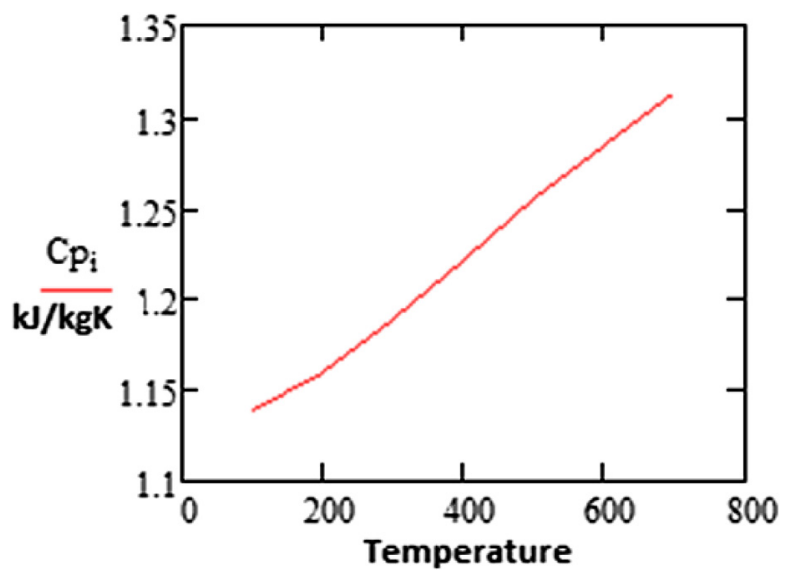

Fig. 3. The specific heat of the exhaust gas variation.
The transferred or absorbed heat in the heats exchangers and in the absorption machine is calculated by:

$Q_{i}=\dot{m}_{i} \cdot C_{p i} \cdot\left(T_{\text {in } i}-T_{\text {out } i}\right)$

The engine block heat loss is calculated using equation (10)

$Q_{\text {lossICE }}=Q_{f u e l}-W_{u}-Q_{e x}-Q_{c w}$

where $Q_{\text {lossICE }}$ is equal to the heat rejection to the oil plus convection and radiation heat transfer from the engine's external surfaces.

The total heat loss in the compact cogeneration system is calculated by equation

$Q_{\text {losssys }}=Q_{f u e l}-W_{\text {eff }}-Q_{H E 1}-Q_{H E 2}-Q_{A M}$

Thermal efficiency of the ICE in the control volume (energy percentage), is usually determined as the ratio of the power output (network) by the fuel energy input and determined by

$\eta_{t h}=\frac{W_{u}}{Q_{f u e l}}$

\subsection{Exergy analysis}

As per literature, exergy can be divided into four different parts. The two main ones are the physical or thermo mechanical exergy and the chemical exergy.

The physical exergy can be expressed as the highest theoretical useful work obtained as a system works together with an equilibrium state takes into account the thermal and mechanical properties (temperature, pressure, enthalpy and entropy) of the stream. The chemical exergy is related with the outgoing of the chemical composition and related to the concentration change with respect to the reference compounds of the dead state of a system. In the combustion process the chemical exergy is a crucial part of exergy. Total exergy can be expressed as follows [31]:

$$
\begin{aligned}
e_{t}= & C_{p} T_{0}\left[\frac{T}{T_{0}}-1-\ln \left(\frac{T}{T_{0}}\right)\right]+R T_{0} \ln \frac{P}{P_{0}}+\sum_{i=1}^{n} X_{i} e_{i}^{c h} \\
& +R T_{0} \sum_{i=1}^{n} X_{i} \ln \left(Z_{i}\right)
\end{aligned}
$$

When evaluating a variation of exergy or exergy flow between two states where the chemical composition of the substance is the same, the chemical contribution cancels, leaving only the difference of thermomechanical contributions [32]. The specific exergy then can be calculated by:

$e_{i}=h_{i}-h_{0}-T_{0}\left(s_{i}-s_{0}\right)$

where $h_{i}$ and $s_{i}$ are flow enthalpy and flow entropy per unit mass at the relevant temperature and pressure, while $h_{0}$ and $s_{0}$ stands for the corresponding values of these properties when the fluid comes to equilibrium with the reference environment.

The exhaust gas can be assumed as a mixture of ideal gases. Then the exergy is calculated as: [33]

$e_{e x i}=C_{\text {pexi }}\left[T_{\text {exi }}-T_{0}-T_{0} \ln \left(\frac{T_{\text {exi }}}{T_{0}}\right)\right]$

The physic and chemical exergies of the air used in the combustion process can be disregarding since the intake air into de internal combustion engine was very close to the reference state in the operations. Likewise, because its properties were almost equal to those in the reference conditions, the thermo mechanical exergy 
of the fuel can also be ignored. Then, the total exergy for a fuel is exactly equal to the chemical exergy multiplied by the coefficient that is the ratio of the chemical exergy and the lower calorific value of the fuel $[34,35]$ and can be calculated by:

$E_{\text {fuel }}=\dot{m}_{\text {fuel }} \cdot L H V_{\text {fuel }} \cdot \phi$

where: $\varphi$ is $1.0-1.06$ for an LPG

The net exergy transfer by heat at temperature $\mathrm{T}$, is given by

$E_{\text {heat }}=\sum\left(1-\frac{T_{0}}{T}\right) Q$

where $\mathrm{T}$ is the temperature at which heat transfer takes place. We considers $\mathrm{T}=313.15 \mathrm{~K}$ (temperature of the system boundary where heat is transferred to the environment) [36].

The exergy produced work is defined by:

$E_{\text {work }}=W$

The rate of exergy destroyed in the control volume due to irreversibilities is calculated but the version of the Gouy-Stodola Theorem [37].

$E_{\text {dest }}=T \dot{S}_{g e n}$

where $\dot{S}_{g e n}$ is the rate of entropy generation in the component. It may also be calculated from ith components:

$E_{\text {idest }}=\sum E_{\text {iin }}-\sum E_{\text {iout }}$

At steady state regime the exergy enters the control volume is equals the exergy exits plus the exergy is destroyed in the system.

The efficiency of the second law of thermodynamics is intended to serve as an approximation measure of a reversible process, is determined with the aid of an exergy balance.

$\xi=\frac{\text { exergy desired }}{\text { exergy used }}=1-\frac{\text { exergy destroyed }}{\text { exergy used }}$

For each sub-system, second law efficiency $\xi$, also known as rational efficiency [34], and $\psi$, also called degree of thermodynamic perfection [35], have been determined according to the equations:

$\xi_{i}=\frac{\sum_{i} E_{\text {desired }}}{\sum_{i} E_{\text {used }}}$

$\psi_{i}=\frac{\sum_{i} E_{\text {out }}}{\sum_{i} E_{\text {in }}}$

The rational efficiencies of the five subsystems presented in Fig. 2 are defined as follows:

$\xi_{\text {ICE }}=\frac{E_{8 a}+E_{3}+E_{6}-E_{7}}{E_{1}}$

The exergy efficiency of the heat exchangers in the system is measured by the increase in the exergy of the cold stream divided by the decrease in the exergy of the hot stream

$\xi_{H E 1}=\frac{E_{10}-E_{9}}{E_{6}-E_{7}}$

$\xi_{H E 2}=\frac{E_{12}-E_{11}}{E_{3}-E_{4}}$
$\xi_{A M}=\frac{E_{13}-E_{14}}{E_{4}-E_{5+W_{\text {pump }}}}$

\section{Results}

\subsection{Energetic balance}

The experimental data, which is given in Table 3 is used to perform the energy and exergy analysis of the engine. The total fuel energy input is $49.03 \mathrm{~kW}$. In Fig. 4 shows the energy balance for the internal combustion engine. The efficiency for the ICE is $26 \%$, this value is according to the others value reports for some researchers, Braga et al. [38] report a thermal efficiency the $22 \%$ for a diesel internal combustion engine working with loads smaller than $50 \mathrm{~kW}$.

In this same figure is shows that the thermal loss from de ICE was $16 \%$ approximately. The insulation of walls of the combustion chamber can reduce the heat rejection from the ICE, but this event will originate a temperature increase of the exhaust gas, consequently increasing the energy loss due to the exhaust gas. As per the equation (10), the energy loss is the difference between the fuel energy input and the sum of heat rejection of energy flow and useful work transfers from the control volume.

Fig. 5 shows the cogeneration system energy balance, the heat loss was $20.7 \mathrm{~kW}$. The thermal efficiency of the system was calculated by equation (12) by considering in the numerator the payload is the water heating load in the heats exchangers and the heat load in the absorption machine for water cooled, this value was $34.3 \%$.

Efficiency achieved in the generation of electricity was $23.5 \%$, finally the overall efficiency $\left(\eta_{\text {global }}\right)$ of the plant reached the $57.8 \%$. We can get a better vision of the energy flows proposed system in the Fig. 6, which represented the Sankey diagram. This diagram represents the quantitative distribution of all existing energetic flows in the system.

\subsection{Exergetic balance}

In this study, test engine was operated at steady state. The numerical results of the exergetic balance are shown in Table 4.

Table 5 shows the destruction exergy, the rational efficiency and the degree of perfection determined for each sub-system. As

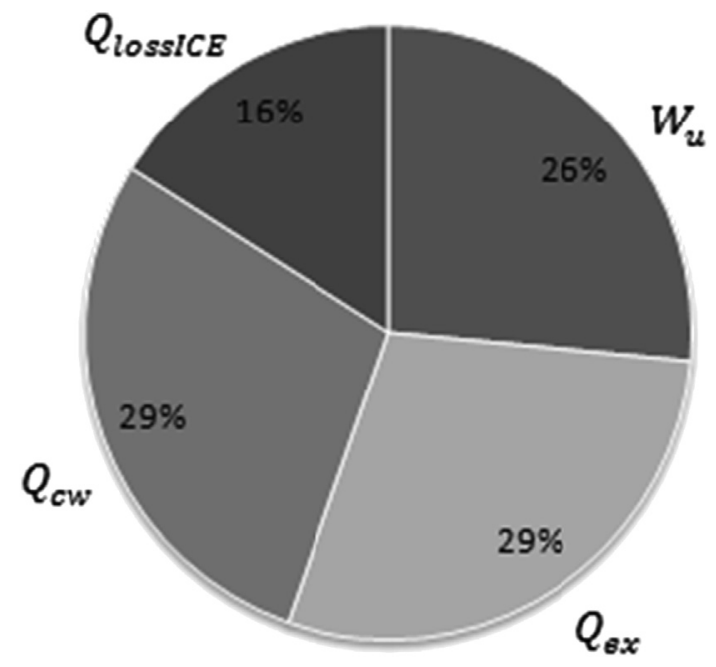

Fig. 4. Energy balance in the ICE. 


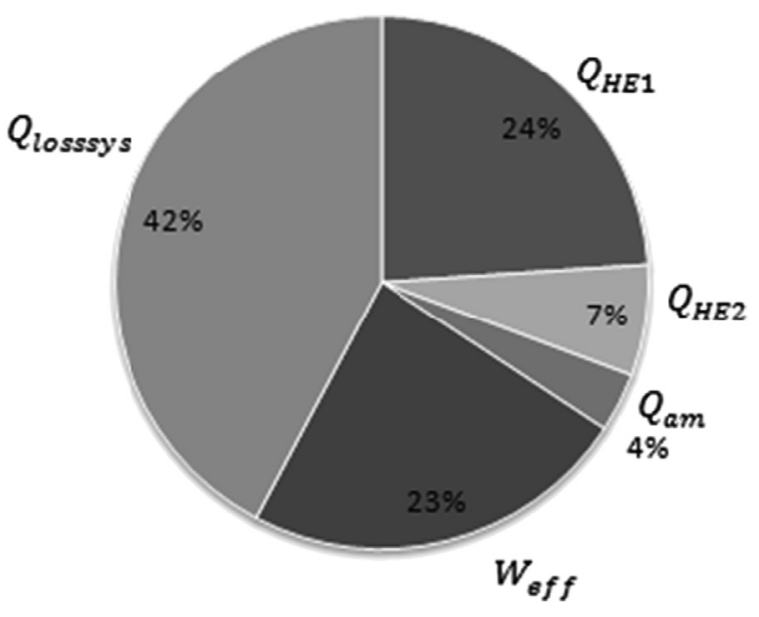

Fig. 5. The cogeneration system energy balance.

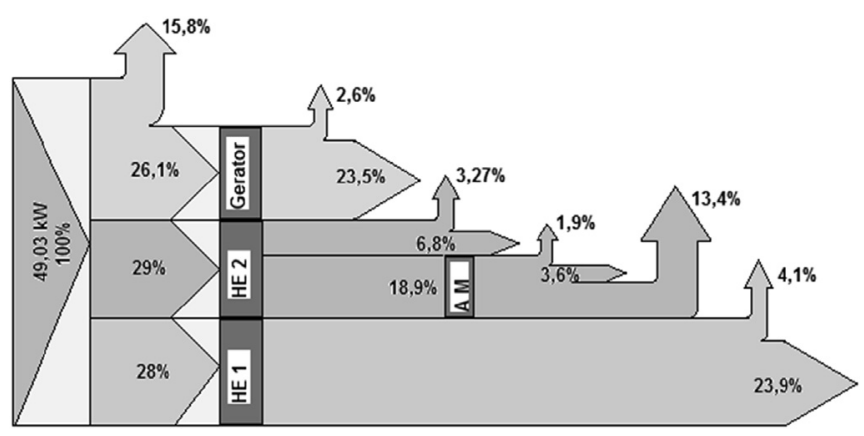

Fig. 6. Sankey's diagram.

expected, rational efficiency shows values lower than those inherent to the degree of thermodynamic perfection for each subsystem analyzed.

From the Table 5 it is possible to observe that the ICE shows a rational efficiency of $39.7 \%$; this value is penalized to a great extent because it a significant fraction of the fuel exergy is destroyed by irreversible processes in the engine, such as combustion, heat transfer, friction, etc. See Fig. 7, which is, as is well known, as the main process in a power generation plant that causes exergy destruction according to $[39,40]$. Although very important, combustion irreversibility is called intrinsic, since it is inherent to the

Table 4

Specific and total exergy in each point.

\begin{tabular}{llcc}
\hline Point & Flow & $\mathrm{e}(\mathrm{kJ} / \mathrm{kg})$ & $\mathrm{E}(\mathrm{kW})$ \\
\hline 1 & LPG & 46,473 & 49.03 \\
2 & Air & 0 & 0 \\
3 & Exhaust gas & 274.29 & 3.719 \\
4 & Exhaust gas & 105.82 & 1.435 \\
5 & Exhaust gas & 23.747 & 0.322 \\
6 & Water & 26.26 & 14.44 \\
7 & Water & 21.63 & 11.90 \\
9 & Water & 0 & 0 \\
10 & Water & 10.35 & 0.726 \\
11 & Water & 0 & 0 \\
12 & Water & 10.35 & 0.726 \\
13 & Water & 0 & 0 \\
14 & Water & 2.467 & 0.057 \\
$8 \mathrm{a}$ & Mechanical work & - & 12.80 \\
$8 \mathrm{~b}$ & Electricity & - & 11.50 \\
\hline
\end{tabular}

Table 5

Irreversibility, rational efficiencies and degree of thermodynamic perfection.

\begin{tabular}{lllrll}
\hline Sub-system & $\Sigma$ Ein $(\mathrm{kW})$ & $\Sigma$ Eout $(\mathrm{kW})$ & $\mathrm{I}(\mathrm{kW})$ & $\xi$ & $\psi$ \\
\hline ICE & 49.03 & 30.959 & 17.693 & 0.397 & 0.639 \\
HE1 & 14.44 & 12.626 & 1.823 & 0.285 & 0.874 \\
HE2 & 3.719 & 2.161 & 2.079 & 0.090 & 0.441 \\
AM & 1.435 & 0.379 & 1.056 & 0.052 & 0.264 \\
Generator & 12.8 & 11.5 & 1.280 & 0.900 & - \\
\hline
\end{tabular}

combustion process. However this value is very close to those reported by Abusoglu and Kanoglu [41] and Sala et al. [42].

The exergetic efficiencies of the HE1 (heat exchanger one), HE2 (heat exchanger two) and AM (absorption machine) are calculated as $28.5 \%, 9.0 \%$ and $5.2 \%$, respectively. This values show that the HE2 and the absorption machine are being the less efficient. Exergy destructions in theses heat exchanges units on the ground are mainly due to the high average temperature difference between the two fluid streams without mixing. It can be culminated that the maximum entropy generation happened in the ICE otherwise of water jacket and exhaust gas heat exchangers.

Fig. 7 shows an entropy generation in the ICE where the cooling water system, which is three times more than the produced in the exhaust gas, this is caused by the difference of the temperatures of the exhaust gas and the cooling water. A cooling water temperature nearly has no fluctuation. In the operating conditions, there is only a $6{ }^{\circ} \mathrm{C}$ fluctuation between the maximum and the minimum temperature. For that reason, the temperature of the cooling water can almost be treated as a constant. This is because the specific heat capacity and mass flow rate of cooling water are superior than exhaust gas. The disparity of the temperature characteristics among exhaust gas and cooling water determines their energy characteristics difference in particular the exergy characteristics. There is also shown in the figure that the heat exergy loss takes part of a small portion of total exergy (1\%), this value is consistent with other researchers refueled as Ramos da Costa et al. [36] and Ameri et al. [43].

The exergetic analysis result is represented in a Grassman diagram as shown is Fig. 8. In the same figure you can sees where the subsystems are appointed and the exergy destruction streams are shown in dark grey.

The exergetic efficiency of the cogeneration system is determined to be $51.19 \%$. The exergy destruction in the cogeneration system engines is about $73 \%$ of the total exergy destruction and $36.0 \%$ of the total exergy input. The $23.49 \%$ of exergy entering the compact system it is converted to electrical power.

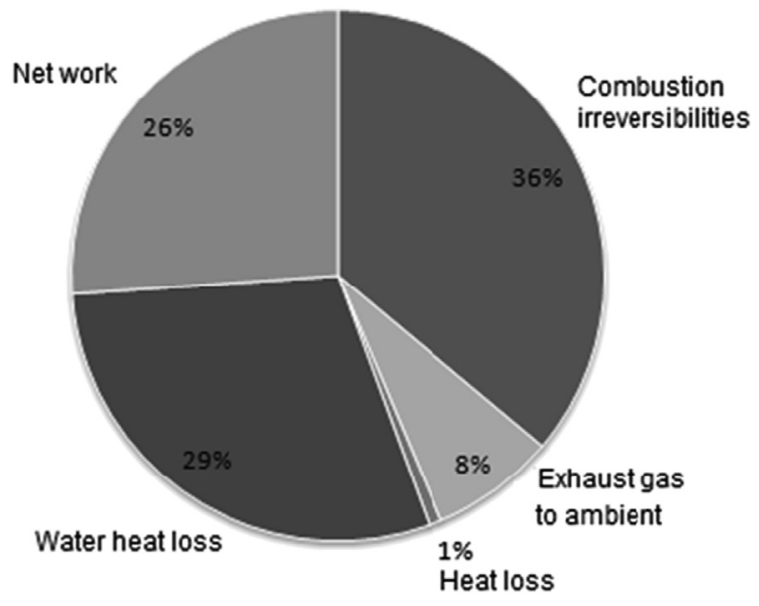

Fig. 7. Exergy distribution in the ICE. 


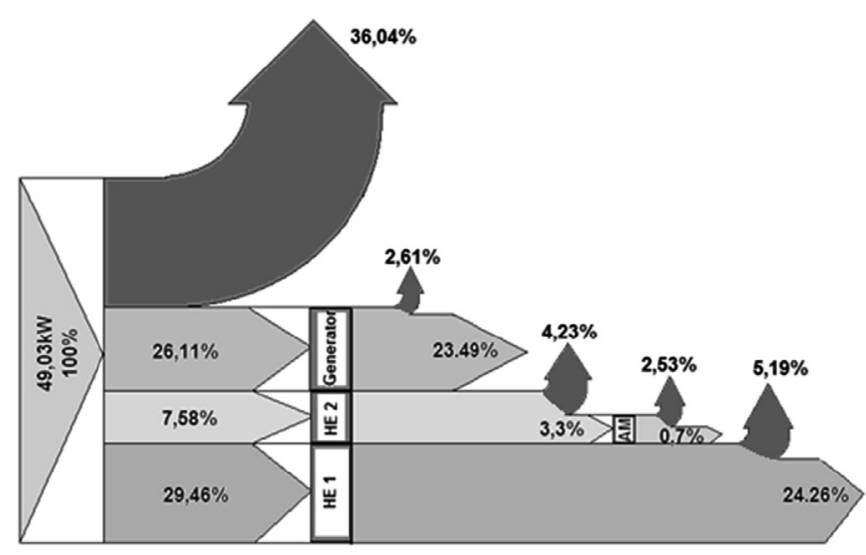

Fig. 8. Grassman diagram.

\section{Conclusions}

The energetic and exergetic analysis procedure has been adapted to a new compact cogeneration system in this paper allowing to identify the sub-systems that present the worst thermodynamic performance. The exergetic performance at rated conditions of each component was calculated and discussed, the results indicate that the engine is by far the most destructive equipment in the system. Small improvements in engine design and operation can provide better enhancements in global system performance compared to large improvements in other components. The high exergy content of the water cool system generated by the ICE justifies the interest in the adoption of a cogeneration cycle for the extraction of a supplementary quantity of heat.

The paper shows that conclusions based in thermal efficiencies are not sufficient to find the best engine performance. Due to technical limitations (irreversibility of the combustion process, heat loss, friction etc.), the combination of exergy and energy analysis was necessary to determine where are the largest irreversibilities in the system and try to find solutions to minimize them. For example the cooling machine for absorption did not performed well since its maximum energy capacity is of 5 TR $(17.4 \mathrm{~kW})$, and its contribution to the system was approximately $3.62 \mathrm{~kW}$. Since the present analysis was applied for an existing system, new operation strategies can arise.

If only power production is considered, it can be seen that the first law efficiency is $23.5 \%$ and the rational efficiency yield are very similar values. On the other hand, considering the combined production of hot water, cool water and electrical power, substantially different values emerge the system efficiency $7.8 \%$ by energetic analysis versus $51.19 \%$ exergetic analysis efficiency.

On the other hand compact cogeneration system applied in the tertiary sector in Brazil is a good technology choice. In this country there are many opportunities to use a system like this, as the vastness of the territory prevents the total connection to the national grid, and there are still many isolated areas.

In addition to these results, this study reveals that a combined energy and exergy analysis provides a much better and more realistic answer.

\section{Acknowledgments}

We are grateful to the Coordination of Improvement of Higher Education Personnel (CAPES), from the Brazilian Ministry of Education (MEC) for their generous funding support to this research.

\section{References}

[1] Sonar D, Soni SL, Sharma D. Micro-trigeneration for energy sustainability: technologies, tools and trends. Appl Therm Eng 2013;71(2):790-6.

[2] Silveira JL, Lamas WDQ, Tuna CE, Villela IADC, Miro LS. Ecological efficiency and thermoeconomic analysis of a cogeneration system at a hospital. Renew Sustain Energy Rev Jun. 2012;16(5):2894-906.

[3] DOE. Combined heat and power: a federal manager's resource guide (Final Report). US Department of Energy, Federal Energy Management Program; 2000.

[4] Soares JB, Szklo AS, Tolmasquim MT. Alternative depreciation policies for promoting combined heat and power (CHP) development in Brazil. Energy 2006;31(8-9):1151-66

[5] Szklo AS. Analysis of Brazil's cogeneration legal framework. Energy Convers Manag 2003:44:369-80.

[6] Dutra RM, Szklo AS. Incentive policies for promoting wind power production in Brazil: scenarios for the alternative energy sources incentive program (PROINFA) under the New Brazilian electric power sector regulation. Renew Energy 2008:33(1):65-76.

[7] Badami M, Mura M, Campanile P, Anzioso F. Design and performance evaluation of an innovative small scale combined cycle cogeneration system. Energy Aug. 2008:33(8):1264-76.

[8] Silveira JL, da A, Walter S, Luengo C. A case study of compact cogeneration using various fuels. Fuel 1997;76(5):447-51.

[9] Rosen MA, Le MN, Dincer I. Efficiency analysis of a cogeneration and district energy system. Appl Therm Eng Jan. 2005;25(1):147-59.

[10] Klaassen RE, Patel MK. District heating in the Netherlands today: a technoeconomic assessment for NGCC-CHP (natural gas combined cycle combined heat and power). Energy 2013:54:63-73.

[11] Liao C, Ertesvåg IS, Zhao J. Energetic and exergetic efficiencies of coal-fired CHP (combined heat and power) plants used in district heating systems of China. Energy 2013;57:671-81.

[12] Lo Basso G, de Santoli L, Albo A, Nastasi B. $\mathrm{H}_{2} \mathrm{NG}$ (hydrogen-natural gas mixtures) effects on energy performances of a condensing micro-CHP (combined heat and power) for residential applications: an expeditious assessment of water condensation and experimental analysis. Energy 2015;84:397-418.

[13] Arcuri P, Beraldi P, Florio G, Fragiacomo P. Optimal design of a small size trigeneration plant in civil users: a MINLP (mixed integer non linear programming model). Energy 2015;80:628-41.

[14] Piacentino A, Gallea R, Cardona F, Lo Brano V, Ciulla G, Catrini P. Optimization of trigeneration systems by mathematical programming: influence of plant scheme and boundary conditions. Energy Convers Manag 2015. http:// dx.doi.org/10.1016/j.enconman.2015.03.082.

[15] P. D. E. Plano Decenal de Expansão de Energia - PDE 2020 Informe à imprensa. Brazil. 2011. p. 1-5 [in Portuguese].

[16] Moura ACM. "Novas tendências de consumo de glp - gás liquefeito de petróleo no brasil". MBA em Engenharia e Negócios de Gás e Petróleo. São Caetano do Sul, SP: Centro Universitário do Instituto Mauá de Tecnologia; 2012 [in Portuguese].

[17] Karamangil MI. Development of the auto gas and LPG-powered vehicle sector in Turkey: a statistical case study of the sector for Bursa. Energy Policy Jan. 2007;35(1):640-9.

[18] B. E. N. Balanço energético nacional. Brazil. 2013 [in Portuguese].

[19] Caliskan HA, Tat ME. A review on exergetic analysis and assessment of various types of engines. Int J Exergy 2008;7(3):287-310.

[20] Celik MB, Balki MK. The effect of LPG usage on performance and emissions at various compression ratios in a small engine. J Fac Eng Arch Gazi Univ 2007; $22: 81-6$

[21] Tira HS, Herreros JM, Tsolakis A, Wyszynski ML. Characteristics of LPG-diesel dual fuelled engine operated with rapeseed methyl ester and gas-to-liquid diesel fuels. Energy Nov. 2012;47(1):620-9.

[22] Lata DB, Misra A. Analysis of ignition delay period of a dual fuel diesel engine with hydrogen and LPG as secondary fuels. Int J Hydrogen Energy Mar. 2011;36(5):3746-56

[23] Lata DB, Misra A, Medhekar S. Investigations on the combustion parameters of a dual fuel diesel engine with hydrogen and LPG as secondary fuels. Int J Hydrogen Energy Oct. 2011;36(21):13808-19.

[24] Lata DB, Misra A. Theoretical and experimental investigations on the performance of dual fuel diesel engine with hydrogen and LPG as secondary fuels. Int J Hydrogen Energy Nov. 2010;35(21):11918-31.

[25] Lata DB, Misra A, Medhekar S. Effect of hydrogen and LPG addition on the efficiency and emissions of a dual fuel diesel engine. Int J Hydrogen Energy Apr. 2012;37(7):6084-96.

[26] Chintala V, Subramanian KA. Assessment of maximum available work of a hydrogen fueled compression ignition engine using exergy analysis. Energy 2014;67:162-75.

[27] B. E. N. Balanço energético nacional 2014. Brazil. 2014 [in Portuguese].

[28] Sanford N, Gregory K. Thermodynamics. Cambridge University Press; 2011.

[29] Robert WG, Don HP. Perry's chemical engineer's handbook. 6th ed. New York: McGraw Hill; 1984.

[30] Moran M. Availability analysis: a guide to efficient energy use. New Jersey: Prentice-Hall; 1982.

[31] Bejan A. Advanced engineering thermodynamics. New York: Wiley; 1988.

[32] Moran HN, Shapiro MS. Fundamentals of engineering thermodynamics. New York: LTC: 2000. 
[33] Torres EA. “Apostila de Análise Exergética”, Escola Politécnica. Brazil: Departamento de Energia, Universidade Federal da Bahia; 2001. p. 31 [in Portuguese].

[34] Kotas TJ. The exergy method of thermal plant analysis. London: Butterworths; 1985.

[35] Szargut J, Morris DR, Steward FR. Exergy analysis of thermal, chemical, and metallurgical processes. NewYork: Hemisphere Publishing Corporation; 1988.

[36] Ramos da Costa YJ, Barbosa de Lima AG, Bezerra Filho CR, de Araujo Lima L. Energetic and exergetic analyses of a dual-fuel diesel engine. Renew Sustain Energy Rev Sep. 2012;16(7):4651-60.

[37] Szargut J. International progress in second law analisys. In: Energy, vol. 5. Pergamon Press; 1980. p. 709-18.

[38] Braga SL, Braga CVM, Pereira R. "Use of natural gas in diesel enginesexperience in LEV/PUC-Rio". Brazil: Technical Reports; 2006.
[39] Sue DC, Chuang CC. Engineering design and exergy analyses for combustion gas turbine based power generation system. Energy Jun. 2004;29(8): 1183-205.

[40] Verkhivker GP, Kosoy BV. On the exergy analysis of power plants. Energy Convers Manag Dec. 2001;42(18):2053-9.

[41] Abusoglu A, Kanoglu M. Exergetic and thermoeconomic analyses of diesel engine powered cogeneration: part 2 - application. Appl Therm Eng Feb. 2009;29(2-3):242-9.

[42] Sala JM, López-González LM, Ruiz de Adana M, Míguez JL, Eguía J, Flores I. Exergetic analysis and thermoeconomic study for a container-housed engine. Appl Therm Eng Nov. 2006;26(16):1840-50.

[43] Ameri M, Kiaahmadi F, Khanaki M. Comparative analysis of the performance of a dual-fuel internal combustion engine for CNG and gasoline fuels. J Power Technol 2012;92(4):214-26. 